\title{
Investigation of Mechanical Properties of Friction-welded AISI 304 with AISI 430 Dissimilar Steels
}

\author{
Anitha. $P^{I^{*}}$, Manik ChandraMajumder ${ }^{1}$, Saravanan. $V^{2}$, Rajakumar. $S^{3}$ \\ ${ }^{1}$ Department of Mechanical Engineering, National Institute of Technology Durgapur, Durgapur. India \\ ${ }^{2}$ Higher College of Technology, Department of Engineering, Mechanical and Industrial Section, Muscat, Sultanate of \\ OMAN. \\ ${ }^{3}$ Centre for Materials Joining \&amp; Research (CEMAJOR), Department of Manufacturing Engineering, Annamalai \\ University, Annamalainagar, Chidambaram, Tamil Nadu, India \\ *Correspondence: anithanitd17@gmail.com
}

\begin{abstract}
In this paper, standard SS304 austenitic stainless steel and SS430 ferritic steel cylindrical rods were fabricated by friction welding process by varying the frictional pressure and forge pressure in order to understand the effect of process parameter. The tensile strength and Vickers micro hardness tests were conducted for each fabricated joint to evaluate the mechanical properties of the welded specimen. It was found that sample S5 with friction pressure of $90 \mathrm{MPa}$ and forging Pressure of $120 \mathrm{MPa}$ has the high tensile strength value of $637 \mathrm{MPa}$ and $372 \mathrm{HV}$ at the interface region. A detailed microstructural analysis was performed at the interface to reveal interconnecting of dissimilar metals.
\end{abstract}

Keywords: Friction welding; Rotational speed; Microstructure; Tensile strength; Hardness

Received: Jun 14, $2019 \quad$ Accepted: Aug 7, $2019 \quad$ Online: Aug 24, 2019

\section{Introduction}

Stainless steels are iron-based alloys containing 8-25\% nickel and 12-30\% chromium, having good corrosion resistance and withstanding for high temperature. Generally stainless steels can be categorized as martensitic, ferritic and austenitic. Austenitic stainless steels represented for the largest production group of stainless steels than any other group. They have a good corrosion resistance in most environments. Austenitic stainless steel can be strengthened significantly by cold working and are often utilized in the applications requiring a good atmospheric or high temperature corrosion resistance ${ }^{[1]}$.

Ferritic stainless steels are basically iron-chromium alloys with body centered cubic (BCC) crystal structure. Chromium content is usually in the range of $11-30 \%$. They have poor strength at higher temperature even though they possess good ductility and formability. It is used in the field of chemical processing equipment, heat exchangers, furnace parts, petroleum refining equipment, solar water heaters, storage vessels, electrical appliances, and house hold appliances where a less severe corrosive atmosphere. Conventional joining of ferritic stainless steel with austenitic steel has many problems because of different mechanical properties for different metal. Such joints can be obtained in a different combinations by solid state welding process $^{[2]}$.

Friction welding is solid state welding process which is most temperate and very gainful joining strategy for disparate metals. The friction welding process producing welds of two workpieces rubbed each other with compressive-force while one is rotating and the other is stationary. The continuous friction of the contact surfaces produced heat at the weld interface and the material became soft. Eventually, the material starts to flow plastically and forms an upsetting at the interface region. Once a certain amount of forging pressure applied, the rotation is stopped and the compressive force is maintained or slightly increased to consolidate the joint. The fundamental parameters of the friction welding process are the pressure, the forging pressure, the duration and the rotational speed. The major advantages of friction 
welding are the capability of joining different metals or alloys, less material wastage, and a short fabrication time ${ }^{[3]}$. This method can also be used to join the different shapes like components of cylindrical or non-cylindrical workpieces. A lot of studies presented on friction welding of similar and dissimilar materials ${ }^{[4-10]}$; however, study based on friction welding of dissimilar austenitic and ferritic stainless steel is scanty.

In this study, parts of the AISI 304 austenitic stainless steel and AISI 430 ferritic steel with equal diameters were welded by the friction welding method. The tensile strengths and micro hardness variation of the joints were determined and correlated with process parameters. Then, the weld visual appearance and microstructures of the welding zones were obtained and investigated using macro- and microphotographs.

\section{Materials and Methods}

Austenitic stainless steel SS304 and SS430 ferritic steel of cylindrical bars with $12 \mathrm{~mm}$ diameter and $75 \mathrm{~mm}$ length were fabricated by means of friction welding. The fabrication of the joints was obtained by a continuous drive frictionwelding machine which is shown in Figure 1. The chemical composition and mechanical properties of the base metals are tested and presented in the Table $\mathbf{1}$ and $\mathbf{2}$. The welded samples were obtained by varying the frictional pressure and forging pressure and maintaining the other parameters such as rotational speed and forging time were constant. In this experiment, the austenitic stainless steel SS304 rod was rotated and ferritic steel SS430 was kept stationary. Figure 1 shows the friction welded sample. The tensile specimens were turned from these joints as per ASTM E8 standards. The ultimate tensile strength for all the joints were evaluated in universal testing machine and further Vickers micro hardness and the microstructural studies are carried out using hardness tester and optical microscope at the welded interface region. The chosen values of the friction welded parameters are presented in Table 3.

\begin{tabular}{llllllllll}
\hline Materials & $\mathrm{C}$ & $\mathrm{Mn}$ & $\mathrm{Si}$ & $\mathrm{P}$ & $\mathrm{S}$ & $\mathrm{Cr}$ & $\mathrm{N}$ & $\mathrm{Ni}$ & $\mathrm{Fe}$ \\
\hline SS304 & 0.08 & 2.0 & 0.75 & 0.045 & 0.03 & $18-20$ & 0.1 & $8-10.5$ & $\mathrm{Bal}$ \\
SS410 & 0.12 & 1 & 1 & 0.04 & 0.03 & $16-18$ & - & 0.50 & Bal \\
\hline
\end{tabular}

Table 1. Chemical composition (wt. \%) of SS304 and SS430

\begin{tabular}{lllll}
\hline Material & Tensile Strength & Yield Strength & \% Elongation & Micro Hardness (HV) \\
\hline SS304 & $621 \mathrm{Mpa}$ & $205 \mathrm{Mpa}$ & 40 & 210 \\
SS430 & $530 \mathrm{Mpa}$ & $310 \mathrm{Mpa}$ & 25 & 180 \\
\hline
\end{tabular}

Table 2. Mechanical Properties of base metals.

\begin{tabular}{llll}
\hline Specimen & Friction Pressure (Mpa) & Forging Pressure (MPa) & Friction Time (sec) \\
\hline S1 & 60 & 90 & 10 \\
S2 & 60 & 120 & 9 \\
S3 & 60 & 170 & 7 \\
S4 & 90 & 90 & 10 \\
S5 & 90 & 120 & 8 \\
S6 & 90 & 170 & 8 \\
S7 & 130 & 90 & 10 \\
S8 & 130 & 120 & 9 \\
S9 & 130 & 170 & 8 \\
\hline
\end{tabular}

Table 3. Friction welded parameters values at the rotational speed (rpm) of 1500 .

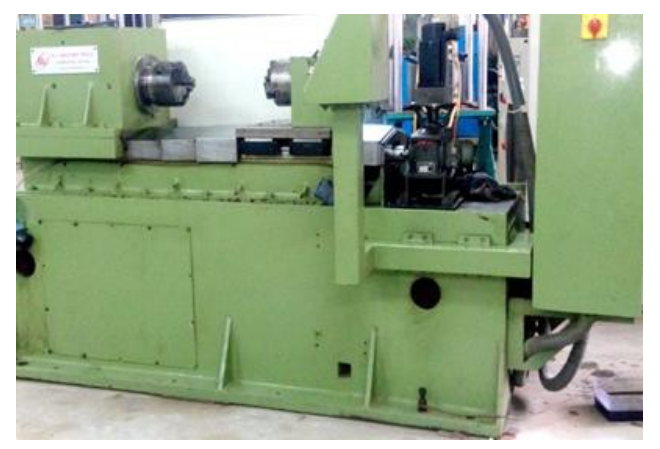

Figure 1. Photograph of Friction welding Machine. 


\section{Results and Discussions}

\subsection{Evaluation of Macro- \& Microstructural Properties}

A defect free dissimilar joint of SS304 and SS430 were made by friction welding procedure by varying the friction pressure and forge pressure and holding other parameters as constant. There is no significant imperfection found in macro image of the welded joint depicted in Figure3. The welding is complete and the flash formation is unsymmetrical due to difference in mechanical properties of dissimilar steels ${ }^{[8]}$. It is obvious from the macrographs that friction pressure and forging pressure greatly affects the geometry of the weld zone and the morphology of the flash. A view of friction weld joints shown in Figure 2 reveals larger flash width increases with incremental of friction pressure and forge pressure. The flash diameter ferritic steel is larger than austenitic steel because of lower thermal conductivity of SS304.The smaller flash diameter exhibits the output of lower friction and forging pressure due to less heat input at interface $^{[9]}$.

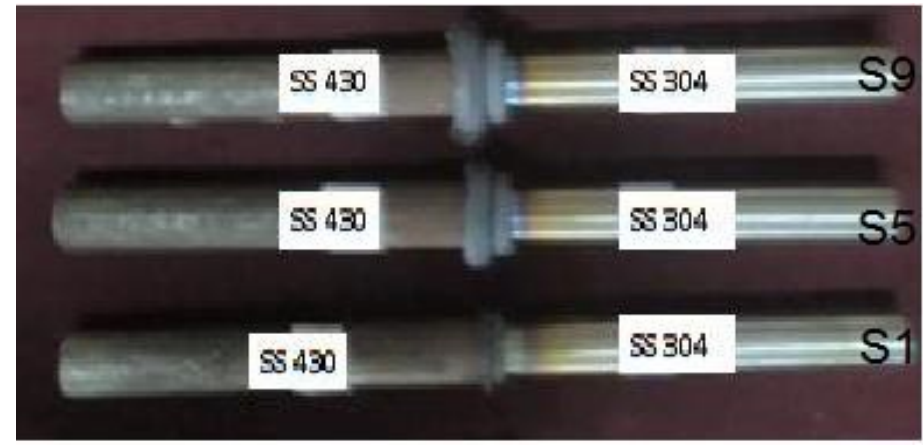

Figure 2. Samples of Friction welded joints.
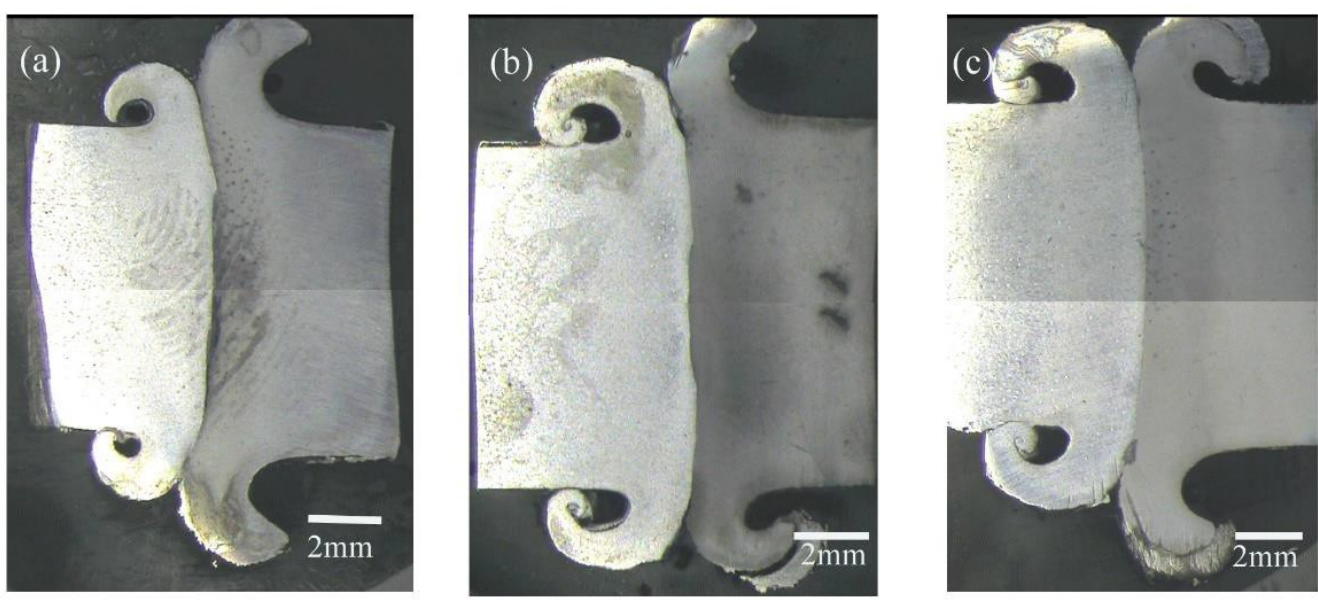

Figure 3. Macro image of weld interface.

Microstructural evaluation of sample S1, S5 and S9 of low, medium and higher level of pre-selected parameters considered for this study was shown in Figure 4. The friction welded joint clearly depicts that three distinct zones were observed namely fully deformed zone (FDZ), partially deformed zone (PDZ) and heat affected zone (HAZ) ${ }^{[10]}$. The most microstructural changes occurred in the FDZ and PDZ regions. The rotational work piece induces frictional heat at the abutting surface to attain high temperature and causes the viscous metal moved towards the central region of the metal. Eventually when friction pressure is applied to unite the joint connected by plastic deformation yielded the dynamic recrystallization. Thus the grain refinement in the interface region of the weld formed. Finally the forge pressure is applied to complete joint with further refinement of grains ${ }^{[11]}$.

High friction pressure give rise to high temperature in the weld interface producing higher orientation intensity and larger expulsion of flashes as revealed in Figure 4c. It is evident that rising the value of friction pressure causes plastic deformation in larger region owing to molten metal and subsequently makes the orientation easier. However, applying forging pressure reduces the HAZ because of high molten area. As the forging pressure is increased the fine grains are noticed on the either side of the weld interface. 

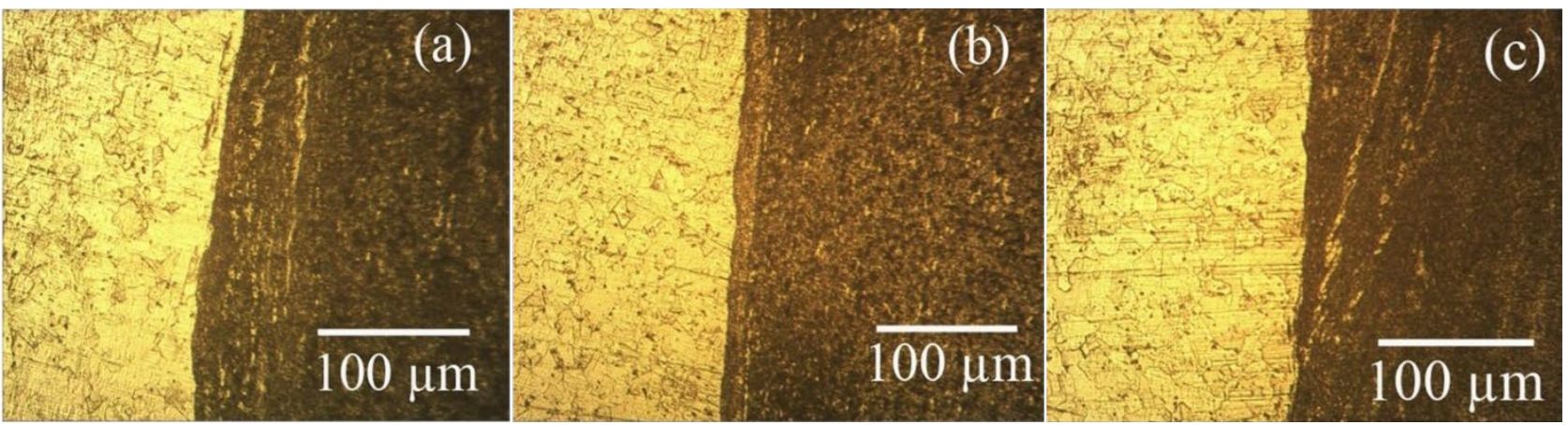

Figure 4. Microstructural evaluation of friction-welded joints.

The low friction pressure and forging pressure depicts the narrow interface region as shown in Figure 4a. At low friction pressure, due to lack of sufficient amount of frictional heat the grain structure is not closely packed and results in incomplete plastic deformation when compared to the sample S5. The sample S5 microstructure reveals the wider heat affected zone with dynamic recrystallization by increasing friction pressure. Subsequently applying forge pressure, the central region consists of equiaxed grains and is confined to ferritic stainless steel. At higher friction pressure speed, the friction heat involved is more results in heating and sudden cooling at this region. This makes the region brittle and results in lower mechanical properties ${ }^{[12]}$.

\subsection{Evaluation of Tensile Strength}

Tensile specimen was prepared as per ASTM E8 standards from the fabricated samples and tested for its ultimate tensile strength using Universal Testing Machine of $1000 \mathrm{KN}$ capacity. The correlation between the tensile strength and the process parameter depicted in Figure 5. It was found that frictional pressure has a great influence on the joint strength. High friction pressure caused more amount of heat led to soften the metal in the frictional surfaces. Hence the soften metal could easily pour out in the direction of rotation and forms more elongated grains in the interface. When the forge pressure is applied the grains became finer, voids became narrower, and are eliminated at the abutting surface due to the local heat added up on the interface region. Thus the tensile strength is much higher in the interface due to the fine grain development of applying forge pressure ${ }^{[13]}$. The low tensile strength $483 \mathrm{MPa}$ was found in sample S1 with friction pressure of $60 \mathrm{MPa}$ and forging pressure of $90 \mathrm{MPa}$.

At low friction pressure there is no adequate amount of heat generated to soften the metal to create a joint and resulted in inferior welding. Eventually applying forging pressure concealed the joint with minor pores. In sample S5 with friction pressure of $90 \mathrm{MPa}$ and forging Pressure of $120 \mathrm{MPa}$ has the tensile strength value of $637 \mathrm{MPa}$. This is due to adequate amount of heat is generated with moderate friction and forging pressure. But when the high friction and forge pressure, the metals to be joined are subjected to high heat and successively cooled at faster rate. But when friction pressure and forge pressure is too high, consequently, the process frictional heat becomes higher and the high heat softens more viscous material, which can lead to expel a large volume of flashes and thinner interface region ${ }^{[14]}$. This enhances the plasticity of the metals making them to soften easily resulting in a lower tensile strength observed at sample 9.

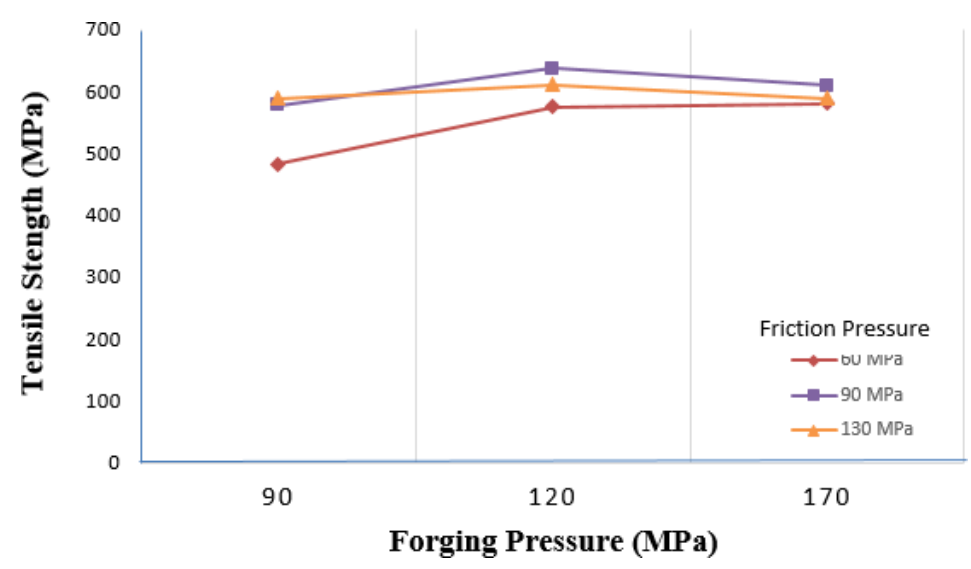

Figure 5. Correlation of tensile strength with friction and forging pressures. 


\subsection{Evaluation of Micro hardness}

The micro hardness variations were attained on Vickers Hardness Testing Machine, the hardness value along the weld interface were obtained by applying a constant load of $500 \mathrm{gf}$ for a dwell period of $15 \mathrm{sec}$. The Figure 6 showed the influence of friction and forging pressure with harness values. It has been observed that weld interface has the higher micro-hardness value compared to the PDZ and HAZ region. This increase in hardness can be related directly to the increasing heat input and plastic deformation ${ }^{[15]}$. At lower friction pressure and low forging pressure the micro hardness value is very less at the interface region because of less frictional heat input. It has been noticed that there is high hardness value at lower friction pressure with higher forging pressure in the interface region. Meantime higher frictional force with lower forging pressure also has higher harness value compared to the samplelvalue. Thus hardness values at the interface are more than that of base metal value due to fine recrystallized grain structure and the presence of intermetallic formed as an output of high heat input and severe plastic deformation.

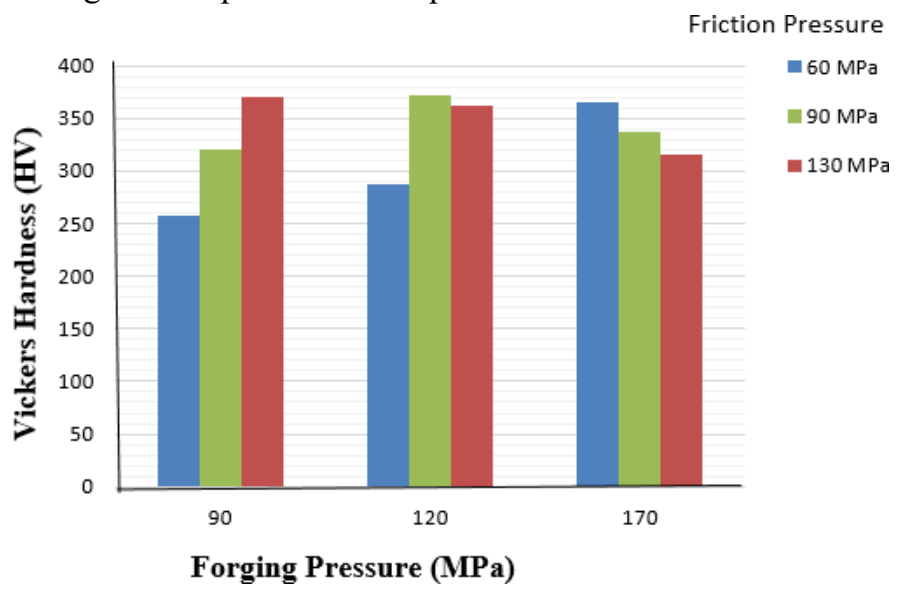

Figure 6. Correlation of micro hardness with friction and forging pressures.

\section{Conclusion}

The AISI 304 austenitic stainless steel with AISI 430 ferritic steel has been carried out by continuous drive friction welding for various friction and forging pressure. From this investigation, the following inferences were arrived:

1. The macro study showed unsymmetrical flash formation of joint and the flash diameter increase with higher friction pressure and forging pressure.

2. Microstructure exhibits fine grains for the higher forging pressure where in increase friction pressure aids dynamic recrystallization with coarse grains.

3. Friction welded joints yielded higher tensile strength than the base material. Higher tensile strength was seen at friction pressure of $90 \mathrm{MPa}$ and forging Pressure of $120 \mathrm{MPa}$.

4. Hardness at interface has higher value than the PDZ and HAZ hardness values at the interface due to fine recrystallized grain structure and the presence of intermetallic formed as the effect of high heat generation and severe plastic deformation.

\section{References}

1. Sahin M. Evaluation of the joint-interface properties of austenitic-stainless steels (AISI 304) joined by friction welding. Mater Des 2007;28:2244-50.

2. Aravindan PSS, Haq AN. Effect of friction welding parameters on mechanical and metallurgical properties of ferritic stainless steel 2007:1076-7.

3. Celik S, Ersozlu I. Investigation of the mechanical properties and microstructure of friction welded joints between AISI 4140 and AISI 1050 steels. Mater Des 2009;30:970-6.

4. Caligulu U, Yalcinoz M, Kati N, Balalan Z, Islak S. The effects of rotation speed and friction time for joining of AISI 4340-2205 steels by friction welding. Metallofiz i Noveishie Tekhnologii 2015;37:665-81.

5. Meshram SD, Mohandas T, Reddy GM. Friction welding of dissimilar pure metals. J Mater Process Technol 2007 ; 184:330-7.

6. Cheepu MM, Muthupandi V, Loganathan S. Friction Welding of Titanium to 304 Stainless Steel with Electroplated Nickel Interlayer. Mater Sci Forum 2012;710:620-5.

7. Chander GS, Reddy GM, Tagore GRN. Influence of process parameters on impact toughness and hardness of dissimilar AISI 4140 and AISI 304 continuous drive friction welds. Int J Adv Manuf Technol 2013;64:1445-57. 
8. Arivazhagan N, Singh S, Prakash S, Reddy GM. Investigation on AISI 304 austenitic stainless steel to AISI 4140 low alloy steel dissimilar joints by gas tungsten arc, electron beam and friction welding. Mater Des 2011; 32:3036-3050

9. Ananthapadmanaban D, Seshagiri Rao V, Abraham N, Prasad Rao K. A study of mechanical properties of friction welded mild steel to stainless steel joints. Mater Des 2009;30:2642-6.

10. Özdemir N, Sarsilmaz F, Hasçalik A. Effect of rotational speed on the interface properties of friction-welded AISI 304L to 4340 steel. Mater Des 2007; 28:301-7.

11. Ma H, Qin G, Geng P, Li F, Fu B, Meng X. Microstructure characterization and properties of carbon steel to stainless steel dissimilar metal joint made by friction welding. Mater Des 2015; 86:587-97.

12. Özdemir N. Investigation of the mechanical properties of friction-welded joints between AISI 304L and AISI 4340 steel as a function rotational speed. Mater Lett 2005; 59:2504-9.

13. Handa A, Chawla V. Investigation of mechanical properties of friction-welded AISI 304 with AISI 1021 dissimilar steels. Int J Adv Manuf Technol 2014; 75:1493-500.

14. Winiczenko R. Effect of friction welding parameters on the tensile strength and microstructural properties of dissimilar AISI 1020-ASTM A536 joints. Int J Adv Manuf Technol 2016; 84:941-55.

15. Kirik, Ihsan \&amp; Ozdemir, Niyazi. Effect of process parameters on the microstructure and mechanical properties of friction-welded joints of AISI 1040/AISI 3041 steels. Mater Tehnol 2015;49:825-32. 